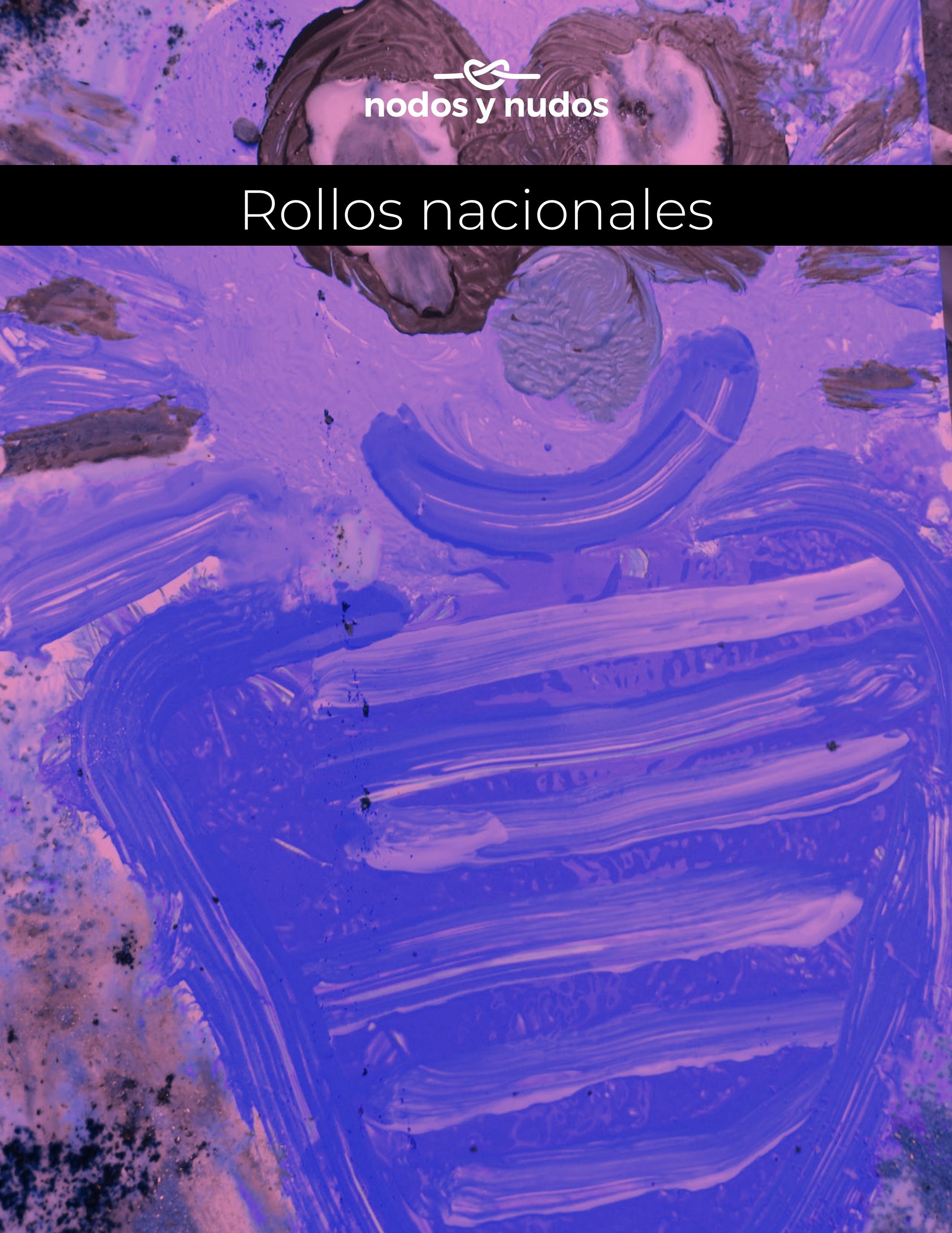




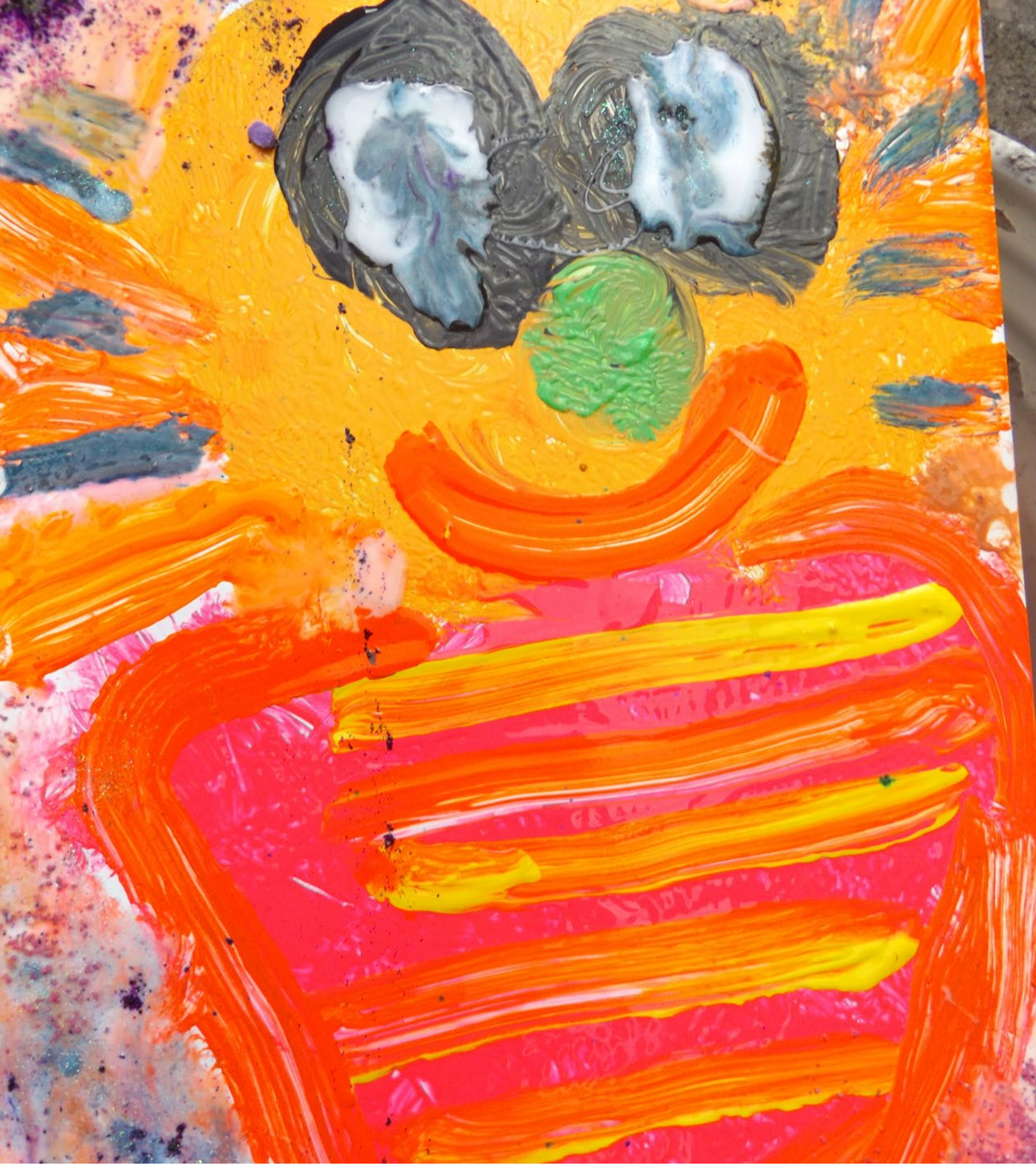




\section{Expresiones territoriales en Usme: una lectura desde la rururbanidad}

Volumen $6 \mathrm{~N} .{ }^{\circ} 47$ julio - diciembre de 2019

ISSN: 0122-4328

ISSN-E: 2619-6069

pp. $37-48$

Territorial

Expressions in Usme:

A Reading from the

Rururbanidad
Expressões

territoriais em Usme:

uma leitura desde a

rurubanidad

\section{Giovanny Eduardo Bogoya Caviedes*}

Fecha de recepción: 02-06-17

Fecha de aprobación: 04-12-19

\section{PARA CITAR ESTE ARTÍCULO}

Bogoya Caviedes, G.E. (2019). Expresiones territoriales en Usme: una lectura desde la rururbanidad. Nodos y Nudos, 6(47). https://doi.org/10.17227/nyn.vol6. num47-6178 


\section{RESUMEN}

El presente artículo, resultado de investigación con jóvenes escolarizados en la localidad de Usme, Bogotá (Colombia), es una apuesta por entender las relaciones sujeto/territorio, desde dos categorias de análisis: espacios rururbanos y expresiones territoriales. Para ello, se utilizó una metodología de investigación cualitativa que combinó instrumentos de observación no participante (matriz de observación), grupos de discusión (matriz textual) y cartografía social (mapas), en torno a la reflexión de los jóvenes sobre el significado y la influencia del espacio geográfico en su cotidianidad. Entre los principales hallazgos, se observa la hibridación que hacen los estudiantes entre los saberes rurales y las prácticas urbanas dentro de su territorialidad, como son: trabajo en el campo, economía agraria, tradiciones familiares, urbanización del territorio, cambio progresivo en el uso del suelo, cuidado del ambiente, formas de vestir, juegos y lenguaje.

Palabras clave: territorio; expresiones territoriales; espacios rururbanos; jóvenes; Usme

\section{ABSTRACT}

This article is a result of research with school youth from the Usme locality (Bogotá, Colombia). It is a theoretical and methodological bet in order to understand the relations between subject territory, under the lens of two analytical categories: rururban spaces and territorial expressions. For this, a research methodology was used that combined non-participant observation (observation matrix), discussion groups (textual matrix) and social cartography (maps), linked to the reflection of the participants about the meaning and influence of the geographical space within their daily lives. Among the main findings is the hybridization that students do between rural knowledge and urban practices within their territoriality, these are: the work in the field, the agrarian economy, the family traditions, the urbanization of the territory, the progressive change in the use of the land, the care of the environment, the ways of dressing, the games, and the language.

Keywords: territory; territorial expressions; rururban spaces; young people; Usme

\section{RESUMO}

Este artigo, resultado de pesquisa com jovens de escola na localidade de Usme, Bogotá (Colômbia), é uma tentativa de entender as relações sujeito / território, a partir de duas categorias de análise: espaços rururbanos e expressões territoriais. Para tanto, utilizou-se uma metodologia qualitativa de pesquisa que combinou instrumentos de observação não participante (matriz de observação), grupos de discussão (matriz textual) e cartografia social (mapas), em torno da reflexão dos jovens sobre o significado e a influência do espaço geográfico em suas vidas diárias. Dentre os principais achados, observa-se a hibridação que os estudantes fazem entre o conhecimento rural e as práticas urbanas em sua territorialidade, tais como: trabalho em campo, economia agrária, tradições familiares, urbanização do território, mudança progressiva no uso de solo, cuidar do meio ambiente, roupas, jogos e linguagem.

Palavras-chave: território; expressões territoriais; espaços urbanos; juventude; Usme 


\section{Introducción}

Este documento surge de una investigación sobre las expresiones territoriales que dinamizan los estudiantes, a partir del uso de los espacios rururbanos de la Unidad de Planeamiento Zonal (UPZ) 58 Comuneros, en la localidad de Usme', realizada en el marco del grupo de estudio en Pedagogía Urbana y Ambiental de la Maestría en Educación de la Universidad Pedagógica Nacional.

El estudio se llevó a cabo en la zona periférica de Usme, por considerar que sus condiciones geoespaciales ofrecen elementos complejos que intensifican las relaciones sociales de las personas que en ella viven. La localidad, ubicada sobre los cerros orientales en el sur de Bogotá, presenta una serie de características que convergen en un escenario en el que se dificulta establecer la frontera en donde inicia lo urbano y termina lo rural, como ocurre, especificamente, en la UPZ 58 Comuneros.

En este contexto surge la siguiente pregunta problémica: ¿De qué manera estos espacios -que denominaré rururbanos- de la localidad de Usme inciden en las expresiones de los estudiantes de educación básica secundaria del Colegio Diego Montaña Cuéllar? Al abordar este interrogante, se intenta dar respuesta al objetivo general de caracterizar la manera en que los diversos espacios, en este caso, de Usme inciden en las expresiones que asumen los jóvenes escolarizados de la UPZ. Para ello, es necesario abordar los objetivos especificos de identificar y describir los espacios, así como las expresiones territoriales y las relaciones que tienen lugar en el entramado sujeto/territorio.

Para establecer un acercamiento a la problemática se planteó un enfoque descriptivo, apoyado en las siguientes herramientas: observación no participante, grupos de discusión y cartografía social. Las categorias nucleares desde donde se leyó el proceso fueron: espacios rururbanos (rururbanidad) y expresiones territoriales, que se abordan en los siguientes

1 Las unidades de planeamiento zonal (UPZ) son una subdivisión urbana de Bogotá agrupada en varios barrios de una misma localidad y cuya área es menor a esta. La función de las UPZ es definir la planeación urbana que requiere la ciudad,; Bogotá se divide en 117 UPZ -7 de estas ubicadas en Usme-. La principal normativa que rige a las uPz es el Plan de Ordenamiento Territorial (РOT), mediante el artículo 49 del Decreto 190 de 2004, Alcaldia Mayor de Bogotá D.C. (2004). apartados, junto con la aproximación a estas, en relación con la educación.

\section{Espacios rururbanos: una contextualización necesaria}

El aumento demográfico de las ciudades latinoamericanas ha producido una transformación de las periferias, tanto en su geografía física como en su geografía humana, cambios que se reflejan en fenómenos como la ocupación de espacios y la urbanización de lugares tradicionalmente rurales. Los procesos de apropiación de los territorios y la consiguiente densidad poblacional dan origen a nuevas expresiones y formas de uso del suelo hibridas, que resultan de una articulación entre lo urbano y lo rural.

Bogotá no ha sido ajena a estos procesos. Desde el último cuarto del siglo xx la ciudad ha sufrido alteraciones tanto en el sistema social como en el físico-espacial, producto de factores como: el aumento acelerado de la población, las políticas públicas, el conflicto armado -sus consecuencias- y los procesos de expansión urbana. Ejemplo de ello es Usme, localidad que en ese periodo sufrió un vertiginoso crecimiento demográfico que dio paso a la construcción de nuevos proyectos de vivienda y unidades residenciales que se estructurarian en barrios, transformando el ambiente natural de la localidad, originando un ambiente construido y diseñado en pro de la urbanización².

Sobre este nuevo panorama surgen estrategias de apropiación del territorio que modifican los escenarios paisajísticos de las periferias. Autores como Barros (2006) proponen la categoria rururbanidad como teorización sobre las consecuencias de la injerencia urbana en dichos espacios: "Los espacios rururbanos hacen referencia a lugares donde se mezclan diversas formas de organización social y territorial, algunas vinculadas con lo urbano y otras con lo rural" (p. 328).

\footnotetext{
2 Según datos de la Cámara de Comercio de Bogotá (2006), Usme fue protagonista de un acelerado crecimiento en su urbanización en los últimos cuarenta años. Los estudios realizados por la entidad se dividen en tres periodos; primero, entre 1973 y 1985 , donde su crecimiento fue superior a otras localidades en 3,10\%; segundo, entre 1985 y 1993, cuando la población de la localidad aumentó en 8,8\%; y por último, en el periodo comprendido entre 1993 y 2005, cuando la localidad presentó el mayor desarrollo demográfico llegando a 46,6 \%. Lo anterior, debido a factores combinados como el POT del año 2000, cuando se declaró a Usme una zona de expansión urbana y destinada a construcción de proyectos de vivienda de interés social (vis), sumado al asentamiento de familias procedentes de otras ciudades.
} 
Definir la categoria de espacios rururbanos implica contextualizar el escenario rural permeado por la expansión urbana en las periferias de las ciudades latinoamericanas. La rururbanidad es un escenario crítico donde concurren determinadas prácticas que modifican las tradiciones culturales de sus pobladores. La categoría debe asumirse como un discurso de la contemporaneidad cambiante, consecuencia de los conflictos sociales, políticos, culturales, demográficos y ambientales característicos desde la segunda mitad del siglo xx:

La proximidad geográfica entre dos lugares centrales no conurbados impulsa la formación de un espacio de contacto entre ellos, de interfase, caracterizado por actividades todavía rurales, en donde los usos del suelo comienzan a ser sustituidos por usos urbanos o subsisten indistintamente, derivando en una coexistencia de sus atributos socioespaciales (rururbanización). (Delgado y Galindo, 2006, p. 209)

El concepto ha aportado a la comprensión de las dinámicas desarrolladas en los espacios urbanos rurales de las grandes ciudades. En América Latina los estudios realizados en Argentina y México se centran en la transformación de las ciudades en sus zonas limitrofes. Es el caso de investigaciones como las de Delgado (2003), y Delgado y Galindo (2008), quienes contextualizan las transformaciones de la relación campo/ciudad y sobre los espacios emergentes que en esta surgen; Aguilar (2002) escribe sobre la periferia expandida en Ciudad de México; Barros (2006) discute sobre la construcción de lugares en espacios rururbanos de la ciudad de Buenos Aires; Sereno, Santamaria y Santarelli (2010) definen la rururbanidad desde el análisis de los significados y la pertenencia al territorio; Ávila (2005) adelanta una investigación cronológica sobre los estudios urbano-rurales en América Latina; y Villalvazo, Corona y Garcia (2002) debaten sobre las fronteras conceptuales que se establecen entre lo urbano y lo rural.

Los espacios rururbanos se estructuran en una suerte de mixtura en la cual se hace difícil establecer en dónde empieza lo urbano y en dónde finaliza lo rural. Parece que se borran las características rurales de los pobladores, y es aqui donde la geografia humana sufre una transformación:
La difusión de nuevos patrones de consumo y hábitos de vida, la megapolización de los sistemas urbanos, los progresos espectaculares de las comunicaciones y la creciente movilidad de la población han modificado radicalmente el patrón de organización del territorio, desplazando o borrando casi por completo las fronteras entre lo rural y urbano. (Linck, 2001, p. 1)

En Colombia los estudios sobre la rururbanidad sostienen la existencia de un espacio rural próximo a las grandes ciudades donde tienen lugar actividades propias del campo y de la ciudad, y convergen la economía y la cultura de cada una de estas:

El concepto de lo rururbano se refiere a aquel territorio en el cual predomina aún el paisaje rural, aunque con una clara huella de la acción del hombre que lo ha transformado, siguiendo los patrones tecnológicos propios de la construcción de ciudad. (Arango, 2009, p. 405)

Esta definición se acerca a las características geográficas y culturales que se desarrollan en gran parte de las zonas periféricas de la ciudad de Bogotá.

Arango (2009) realiza una caracterización demográfica sobre la población que habita en estos lugares:

En general, las familias perciben una parte de su ingreso de actividades rurales que permanecen principalmente a cargo de las personas mayores -agrícolas y pecuarias-, mientras que otra parte del ingreso proviene de actividades urbanas que desarrollan especialmente los jóvenes y que están ligadas a los servicios personales, a la economía del rebusque, a empleos de baja remuneración y no muy poco exigentes en el nivel de capacitación. (p. 405)

De esta manera, los espacios rururbanos cumplen determinadas características demográficas, topográficas y culturales, que determinan la cotidianidad y las formas de vida de las personas que alli habitan. Surgen factores culturales que se arraigan a la geografía del lugar y que determinan unos constructos sociales propios de los espacios urbano-rurales.

Según Arango (2009), los espacios rururbanos presentan un panorama crítico debido a la situación de la frontera rural que ha sido abandonada por las politicas públicas y al proceso de urbanización que transforma la economía, demografía y cultura de estos 
lugares. Otras investigaciones realizadas en el pais, son las de Fraume (2002), sobre el fenómeno físico del rizoma y su relación con lo rururbano; Zuluaga (2005), quien presenta las dinámicas territoriales que se desarrollan en la frontera rural-urbana; la teorización sobre el concepto rururbano desde un estudio histórico de la conformación de territorios, de Fernández (2007); el estudio de Bahamón (2009) sobre el nuevo paisaje de las periferias y las manifestaciones urbanas en el ámbito rural; y el de Castaño (2014), que aborda la rururbanidad desde la composición poblacional y los estilos de vida que en ella se entretejen.

En resumen, los espacios rururbanos son escenarios estratégicos para la transición entre el campo y la ciudad, se estructuran en zonas geográficas que responden a caracteristicas rurales ubicadas en los bordes de las ciudades, las cuales son modificadas constantemente en su geografía física y humana debido a la intervención urbana en su territorio. Aunque los espacios rururbanos se ubican en las partes periféricas de las ciudades, no todos sus límites urbanos responden a espacios rururbanos y tampoco todos sus espacios rurales próximos configuran un espacio rururbano.

Usme es una de las localidades más extensas de Bogotá - la segunda después de Sumapaz- y la octava en población. Del total de sus $210 \mathrm{~km}^{2}$ de superficie, $25 \mathrm{~km}^{2}$ pertenecen al área urbana y $185 \mathrm{~km}^{2}$ a la zona rural. Entre estas se presentan fuertes contrastes por sus características geográficas, relieve, hidrografía y clima.

La localidad se divide en siete unidades de planeamiento zonal (UPZ), que a su vez se fraccionan en 279 barrios y 30 veredas (SDP, 2011). Una de ellas es la UPZ 58 Comuneros, cuya estructura se fracciona en 55 barrios, entre los cuales se encuentra Usminia. En este se ubica la Institución Educativa Distrital Diego Montaña Cuellar, cuya zona de influencia escolar abarca barrios aledaños como Antonio José de Sucre, Monteblanco, Villa Anita, Serranías, La Esperanza, El Tuno, El Uval y Centro Usme, en los cuales se mezclan espacios con características urbano-rurales sobre la periferia de la ciudad. Por esto, es de considerar que existe en ellos una hibridación territorial que se puede denominar espacio rururbano.

\section{Expresiones territoriales: una teorización desde el uso del espacio}

Aunque en Colombia el concepto expresiones territoriales no ha sido estudiado de manera rigurosa, en Latinoamérica si se encuentran trabajos desde campos disciplinares como la geografía y la antropología, principalmente en Argentina, Chile y México.

Los estudios ofrecen una manera de entender el territorio desde la concepción de las prácticas sociales determinadas por un paisaje físico: "las aportaciones y los desarrollos que se han hecho desde la geografía y la antropología muestran detalladamente los procesos en que emergen novedosas expresiones territoriales donde aún persiste lo viejo, el rural profundo" (Ávila, 2005 , p. 49). Desde la geografía se plantea la articulación del paisaje físico con los hábitos de vida cotidianos y desde la perspectiva antropológica se propone un estudio sobre las sociedades tradicionales y su afectación en el territorio.

Ávila (2005) se refiere así a las expresiones que se dan en los espacios rururbanos:

De ahí que se produzcan situaciones y actividades específicas derivadas del empalme o superposición de lo urbano, con fenómenos y manifestaciones propias de los ámbitos rurales, lo que genera una simbiosis con expresiones territoriales determinadas. Dichas manifestaciones se expresan tanto en el contexto de las actividades productivas, de la cultura de quienes ahi habitan, del medio ambiente, como de la propiedad de las tierras, entre otras, en situaciones muy especificas. Se trata del reconocimiento de territorios o ámbitos simbióticos, donde se expresan situaciones o actividades inherentes a lo urbano y lo rural, en un marco físico donde la presencia de la ciudad es determinante en la organización del territorio. (p. 20)

De este modo, se señalan los alcances de dichos espacios no solo en la reconfiguración del territorio fisico, también en la transformación y establecimiento de prácticas sociales determinadas por la alteración del territorio.

Entre los autores que también abordan el concepto expresiones territoriales se encuentran Rubio (2010), quien estudia los procesos de apropiación de 
los territorios a través de los mercados laborales; Molina (2011), que lo aborda desde la singularidad de la regiones y su pluralidad de habitantes, y entiende el territorio como un espacio de poder y disputa entre los diversos actores sociales que en él conviven, principalmente en ámbitos rurales y urbanos que se transforman constantemente; Boldrini y Malizia (2014) analizan la gentrificación, las relaciones políticas y económicas, y los diferentes tipos de lucha en defensa del territorio; Palma (2007) estudia las relaciones territoriales desde la producción económica y desde la organización sociopolítica. Para Vargas (2009), las expresiones territoriales hacen referencia a las nuevas formas de uso y ocupación del territorio; el término está ligado intrínsecamente a la economía, a los mercados imperantes y a la modernización agrícola, lo que genera una profunda transformación en los modos de producción y de los patrones de ocupación del territorio.

La noción expresiones territoriales no se reduce a un espacio fijo, por el contrario, se desenvuelve en los ámbitos urbanos, rurales, rururbanos o en cualquier otro lugar que sea modificado por la acción humana. El concepto es utilizado para explicar las relaciones entre ciertas conductas humanas con el territorio. Ávila (2005) categoriza ciertas prácticas sociales en el contexto urbano:

Esta situación se plantea a partir de la misma complejidad que tiene en sí este tipo de expresiones en ese ámbito simbiótico, y donde hay una serie de cambios, tanto en los procesos territoriales como en las formas de análisis de los mismos; dichas transformaciones están presentes y se reconocen los cambios en las jerarquías espaciales, sobre todo en la jerarquía urbana. (p. 43)

En el territorio coinciden una serie de experiencias que se hacen visibles en la transformación de su naturaleza, las cuales determinan los procesos sociales de la contemporaneidad:

En el territorio se mezclan las huellas de la naturaleza, más o menos transformada. En el territorio se materializan los procesos espaciales contemporáneos y su aspecto visible se aprecia en los diferentes paisajes. En cada lugar particular se concentran las lógicas más generales de la producción económica y social y lo hacen de acuerdo a sus respectivas normas y pautas de organización sociopolítica y cultural. (Palma, 2007, p. 28)
Las expresiones territoriales consisten en una identidad, uso y apropiación sobre el territorio, el cual adquiere una notable importancia en la vida social de las personas; se expresa en un ejercicio de control, dominio e identificación de determinados lugares mediante procesos complejos en los cuales se concretan relaciones, vivencias y experiencias. Se resalta entonces lo expuesto por Larraín (2001), quien asume al ser humano como un ser histórico, puesto que vive en una dimensión temporal, y como un ser territorial, debido a que organiza su vida en espacios limitados a los que les otorga significados. De esta manera, las personas territorializan un espacio geográfico, les brindan significados y sentidos que contribuyen de manera importante a la configuración de identidad sobre el territorio, lo cual se entiende en este trabajo como expresiones territoriales.

Entonces, las expresiones territoriales se manifiestan en costumbres, hábitos, actividades, comportamientos, conductas, prácticas que asumen las personas desde y dentro de un territorio. Para el objeto de esta investigación se intentó identificar cuáles son las expresiones territoriales de los estudiantes en los espacios rururbanos de Usme.

Con el propósito de entender las expresiones de los jóvenes en una espacialidad rururbana, la presente investigación centró su análisis en la zona rururbana de Usme, en espacios donde se generan una serie de expresiones de identidad y usos sobre el territorio, en la perspectiva propuesta por Molina (2011): "El territorio genera una profunda valoración emocional, su historia, las tradiciones, paisajes, modos de habitar el espacio y todas aquellas manifestaciones culturales dan singularidad a una región o localidad" (p. 9).

De acuerdo con lo anterior, aspectos como el clima, los accidentes geográficos y la extensión de la zona son reelaborados simbólicamente por las personas, lo que da origen a expresiones territoriales definidas que se manifiestan en la cotidianidad de las prácticas sociales, modos de hablar, usos del espacio, cuidado del ambiente, maneras de vestir, acciones productivas que identifican a los habitantes de algunos lugares. Las expresiones territoriales en relación con la rururbanidad están densificadas por lo que ocurre en el contexto en que habitan los sujetos, 
en este caso, la zona porosa entre lo urbano y lo rural. Se puede pensar que las expresiones territoriales de la rururbanidad responden a las dinámicas de transformación acaecidas en los últimos años y que tienen como resultado cambios en las prácticas económicas, culturales y sociales de los vórtices que empalman a las ciudades con el campo.

Las expresiones territoriales de un sujeto no son resultado de una relación individual con el territorio, sino que devienen de procesos de subjetivación en relación con otros sujetos, en el marco de entramados de sentido y significado conexionados con el contexto geocultural. De ahí la importancia de examinar las relaciones entre lo rururbano, las expresiones territoriales y la escuela, en la medida en que, en esta última, desde la institucionalidad emplazada en un territorio, transitan saberes y manifestaciones asociadas a las características geográficas y socioculturales que están más allá de los muros, pero que encuentran convergencia en el interior de estos. Aquí adquiere valor indagar sobre este entrelazamiento, aunado a la carencia de estudios que articulen el tema de la rururbanidad con el ámbito educativo.

\section{Conociendo la upz desde la mirada de los estudiantes}

En Usminia pasa el río Tunjuelo, está el parque Cantarrana, hay cultivos de alverja, hay fincas en donde se crían vacas, se vende leche y huevos baratos. Pero más abajo hay venta de drogas, pelados que consumen, están los barristas y es peligroso, como en la ciudad.

Lizeth Verónica Castellanos Toro

Se trabajó con una metodología descriptiva, de corte cualitativo, con la intención de identificar y describir las expresiones territoriales de los estudiantes en sus relaciones dentro de la rururbanidad, así como las influencias del territorio sobre aquellas. Se buscó comprender, a través de la observación, los comportamientos que asumen los estudiantes como grupo social permeados por el contexto geográfico. Las expresiones territoriales fueron descritas partiendo de la observación analítica para entender el fenómeno social desde la experiencia de los jóvenes, en la perspectiva de interpretar la cultura y comprender cómo se construyen las subjetividades, como lo plantea Caballero (2015).

Se hizo una aproximación al contexto observable en la cotidianidad de los estudiantes, a través de sus expresiones, relatos y narrativas. Para ello se utilizaron las siguientes técnicas e instrumentos: observación no participante (matriz de observación), grupos de discusión (matriz textual) y cartografía social (mapas).

»

Observación. Durante 2016 (febrero a noviembre), se hizo observación de las expresiones de los jóvenes cuando interactúan entre pares, tanto dentro como fuera de este (parques, zonas verdes de los barrios aledaños). Posteriormente, los registros obtenidos se pasaron a una matriz de observación, que condujo a unos resultados que se pueden describir de la siguiente manera:

Para jugar y compartir con sus amigos, los jóvenes disfrutan de los espacios naturales que les ofrece la rururbanidad, se les da prevalencia a juegos de contacto físico más que al uso de herramientas tecnológicas. Respecto a su comunicación se evidencia el dominio de un lenguaje juvenil citadino, al hacer uso de expresiones que representan amistad o compañerismo, como: parce, cucho, perro, ñero, chinche, socio, niga (negro); algunas expresan desagrado, como: pescado (feo); y otras representan acciones o actividades: roli (vuelta), parla (conversar), veo (listo), roña (hacer pereza), güiro (pelea), sicas (aprobado), curtir (fastidiar), farra (fiesta), suave (fácil), marearse (miedo). Asimismo, la presencia de elementos o dinámicas propias del campo, como fincas, agricultura, campesinos y animales son aceptados por los jóvenes, aunque no influyen en su manera de vestir, debido a que la ropa responde a la moda juvenil urbana del sector, que se caracteriza por prendas propias de tribus urbanas, como barristas, hoppers, skaters, entre otros. Por último, se observan expresiones en pro del cuidado de la naturaleza por parte de los jóvenes. 
Grupos de discusión. Se realizaron entrevistas grupales con estudiantes entre 12 y 17 años, de la sede A del Colegio Diego Montaña Cuellar, organizados en 4 grupos preseleccionados de 10 estudiantes cada uno. Con ellos se trabajó por separado durante 60 minutos, posteriormente, en un segundo encuentro se socializaron las respuestas dadas a las 10 preguntas orientadoras, con el fin de buscar variantes de respuesta frente a los objetivos específicos de la investigación. Entre los principales resultados de los grupos de discusión, se encontraron los siguientes:

Los estudiantes expresan que viven en un espacio urbano-rural, en el cual se encuentran elementos naturales que existen en el campo, como animales propios de estos lugares, campesinos, fincas y agricultura; pero también factores propios de la ciudad como la urbanización de los espacios, sistemas viales, comercio, actividades industriales e infraestructura. De esta manera, consideran que cerca del colegio se viven, al mismo tiempo, dinámicas tanto del campo y como de la ciudad. En relación con lo económico, los estudiantes identifican las formas de economía predominantes en el escenario rural, al expresar que en el territorio hay agricultura, ganadería, porcicultura, cría de ovejas, gallinas, producción y comercialización de productos lácteos, principalmente. También, se observa que, aunque predomina el paisaje rural en la UPZ, los estudiantes mencionan el cambio progresivo en el uso del suelo que ha tenido la localidad, debaten sobre las consecuencias de la urbanización del territorio con las construcciones de nuevos proyectos de vivienda, como es el caso del Parque Ambiental Cantarrana y Usme Pueblo, en los cuales se consolidan nuevos conjuntos residenciales que afectan el ecosistema rural de la zona.

Cartografía social. Con esta técnica se buscó una aproximación a los espacios contiguos a la institución, desde la mirada de los estudiantes. Se trabajó en tres fases: selección de participantes e inducción; recorrido por el territorio, y ejercicio de mapeo. Como resultado, se elaboraron cuatro mapas en donde los estudiantes representaron los lugares más significativos de la UPZ y las actividades que alli más practican.

A partir de este ejercicio, se encuentra que los escenarios más recurrentes en los mapas son: zonas verdes, parques, canchas de microfútbol, fincas y fuentes hídricas (rio Tunjuelo, quebrada Chuniza, quebrada El Piojo). Los elementos más visibles en los mapas son: árboles, montañas, quebradas, animales (vacas, caballos, burros, ovejas, marranos, conejos, gallinas), casas y vehículos. En relación con las expresiones que se pueden identificar en los mapas, se encuentran: el juego (con balones, frisbee, elevar cometa, en los árboles), nadar en el río, descansar y compartir en las fincas y potreros, cuidar los espacios naturales, observar los animales y hacer uso de los alimentos ofrecidos por la agricultura, en especial, lácteos y huevos. En este aspecto, se destacan las expresiones de compañerismo, dinamizadas por las relaciones que se tejen en el territorio y el uso predominante de espacios que han sido propios de lo rural, para su recreación, interacción y descanso.

\section{Conclusiones y recomendaciones}

La implementación de las tres técnicas permitió encontrar una serie de coincidencias en sus resultados: el uso de las zonas verdes como escenarios de encuentro para la recreación; el juego como medio de conexión entre la relación sujeto/territorio; la descripción de los lugares cercanos a la institución como espacios donde la naturaleza se articula con la ciudad; la prevalencia de parques y fincas como lugares predilectos para los jóvenes de la UPZ; la importancia del colegio como territorio de convivencia y referencia del barrio; la presencia de dinámicas propias del campo que se dinamizan cerca del lugar de residencia de los estudiantes; la influencia de la moda juvenil urbana del sector; las consecuencias ambientales que trae la urbanización del territorio; la transformación en el uso del suelo que ha tenido la localidad, la identificación de factores urbanos dentro de la territorialidad de Usme, y la significación que le dan los jóvenes a las amplias zonas naturales entendidas como rurales. 
Retomando las ideas de Molina (2011) sobre las manifestaciones que dan singularidad a una región, se puede afirmar que existe un anclaje afectivo de los estudiantes en el territorio, sus elementos y la tradición del agro:

Donde yo vivo hay montañas, hay animales y hay muchas fincas; para mí, hago de cuenta que vivo en el campo. (Ricardo Timana)

Estos animales solo pueden vivir donde hay campo, montañas, quebradas, así sea cerca o en medio de la ciudad, me gusta vivir acá. (Lorena Villarreal)

Se encuentra que los jóvenes generan vínculos con los espacios a través del juego y el cuidado del ambiente:

Hay muchas zonas verdes, en donde jugamos todos los dias, las cuales dan como una liberación. Es bueno tener campo cerca al barrio, uno puede descansar en la naturaleza, jugar y cuidar los arboles, además hay tiendas para comprar. (Estid Canchón)

De alguna manera se observa una hibridación de saberes rurales (trabajo en el campo, economía agraria y tradiciones familiares) que se mezclan con unas prácticas urbanas (formas de vestir de los jóvenes, sus juegos o lenguaje que utilizan entre compañeros):

Hacemos labores propias del campo como rociar el agua a las plantas, cultivar la cebolla, ordeñar las vacas, dar de comer a las gallinas, recoger los huevos, y si me gusta hacerlo porque sirve para cuidar el medio ambiente. (Luisa Rico)

Si hay campesinos, su modo de vestir es con botas, un pantalón, una camisa de rayas y su acento es como del campo, se visten con ruanas, botas de caucho, sombreros y llevan machete. Aunque, mi manera de vestir es distinta, porque me visto según mi manera o estilo que nada tiene que ver con ellos. (Durley Figueroa)

Es decir, no se podría hablar de una jerarquización de lo urbano sobre lo rural, o a la inversa; se puede definir, en cambio, una estructura espacial rururbana en donde los jóvenes consolidan sus expresiones.

Respecto al tipo de expresiones que se pueden clasificar como territoriales, aparecen aquellas en donde los jóvenes utilizan los espacios para interactuar, como los juegos y el uso que hacen de las zonas rurales, así como los lazos afectivos que establecen con la actividad agrícola, animales, campesinos, alimentos y el ecosistema. De esta manera, en el territorio, ejercen su subjetividad como seres sociales, muestra de ello son las percepciones, sentimientos y lenguaje que emplean en esos espacios donde habitan: lugares de agrado, costumbres familiares y modos de comunicación:

Siempre me ha gustado vivir acá, ayudando a mis papas en el trabajo del campo, lo que cultivamos, los animales que cuidamos, ir al colegio, que me quede cerca, tener donde jugar, subirme a los arboles, me siento orgulloso de mis abuelos campesinos que viven conmigo y me enseñan día a día a cuidar el lugar donde vivo, a conservar esas tradiciones. (Svenson Nocobe)

Tanto en las técnicas de cartografía social como en la observación, los jóvenes demuestran un interés por proteger el ecosistema rural de la periferia de Usme, al manifestar su inconformismo sobre el vertiginoso proceso de urbanización que ha venido sufriendo la localidad, en especial, las afectaciones del Parque Ambiental Cantarrana y las fuentes hídricas cercanas a la institución; además de las construcciones cerca del parque fundacional, que han deteriorado el patrimonio arquitectónico y cultural de Centro Usme:

Vivo en medio del campo y la ciudad porque hay gente que vive en fincas y eso se ve como si fuera campo, pero realmente es la ciudad, hay muchas zonas rurales, pero también hay apartamentos y diferentes tipos de casas que han construido últimamente, sobre todo en Usme centro y cerca al Cantarrana, lo que daña el ecosistema. (Dayanna Cristancho)

En relación con la pregunta sobre los vínculos que tendría la rururbanidad con la educación, se evidencia que las expresiones sobre juegos, habla, cuidado del ambiente, identidad, pertenencia, ocio, se intercalan en el escenario escolar en discurso (habla) y en práctica (juegos), siendo estas la manera como los sujetos construyen dinámicas de apropiación del territorio:

Intento cuidar las zonas verdes del colegio, igual que las fincas, me gusta vivir en Usme, ver animales, compartir con campesinos, tener amigos que viven en fincas, poder jugar con ellos, hablar, visitarlos, conocer cómo viven, 
cómo cultivan, comer los alimentos del campo, respirar aire puro, hablar de todo eso con mis amigos aqui y afuera del colegio. (Kevin Bonilla)

Se destaca la proximidad entre lo rururbano y la escuela, el juego como medio de conexión tanto en el interior como fuera de la institución educativa, la articulación entre naturaleza/ciudad, el colegio como lugar de transmisión de saberes en torno a lo rural, debido a que en él tienen lugar acciones como el cuidado de la naturaleza, el consumo de alimentos proporcionados por las fincas vecinas o la identidad que generan hacia las tradiciones agrarias, y la identificación que hacen los estudiantes de la frontera urbano-rural en donde se emplaza la institución, la cual se ubica en la zona porosa de Usme y es representada por los jóvenes en el ejercicio de cartografía social.

Entonces, los trabajos pedagógicos que indagan sobre la relación entre sujeto y territorio se pueden potencializar en la medida que las instituciones presentes en las fronteras urbano-rurales desarrollen proyectos educativos territorializados que involucren el análisis de lo rururbano y sus expresiones territoriales desde el contexto escolar, lo que implica efectos directos en el currículo. Es el caso de la IED Diego Montaña Cuellar, cuyo Proyecto Ambiental Escolar (PRAE) trabaja sobre las condiciones geográficas, ambientales, culturales, laborales y migracionales, especificas de la localidad de Usme.

La relación rururbanidad-educación adquiere mayor importancia si se tienen en cuenta los fenómenos de extensión urbana presentes en las zonas periféricas de la ciudad, la gran cantidad de establecimientos educativos que se emplazan en estas zonas $y_{\text {, en este }}$ caso específico, la numerosa población de niñas, niños y adolescentes en edad de escolarización que habitan en la localidad. Estas condiciones pueden contribuir a consolidar proyectos educomunitarios que aporten en la formación de sujetos que se empoderen de expresiones territoriales en torno a su relación con el ambiente desde una lectura de su contexto.

Se requieren nuevas apuestas pedagógicas que indaguen sobre líneas de investigación que exploren el contexto fronterizo, como pueden ser: pedagogía rururbana; educación y cuidado ambiental; espacio, territorio y escuela; dinámicas socioespaciales en el territorio urbano-rural; conservación de lo rururbano desde el escenario escolar; identidad rururbana y espacio público; entre otras, que rastreen sobre la relación que se teje entre sujeto y territorio desde la frontera urbano-rural.

Al mismo tiempo surgieron interrogantes sobre la analogía educación-territorio. Primero, acerca de la viabilidad de teorizar el concepto de pedagogía rururbana, tanto desde la institucionalidad de la escuela como fuera de esta: ¿Qué tipo de alcances tienen los juegos en la conexión entre educación y territorio?; ¿Cómo podría la articulación entre naturaleza y ciudad originar dinámicas de desarrollo desde el cuidado del ambiente? Segundo, sobre la relación expresiones territoriales/pedagogía: ¿En qué sentido las expresiones territoriales pueden dinamizar prácticas en el aula o en la escuela? ¿De qué forma la expansión de lo urbano determina expresiones que legitiman la reducción de lo rural? Son interrogantes que siembra la investigación y que pueden ser retomadas en posteriores trabajos.

\section{Referencias}

Aguilar, A. (2002). Las mega-ciudades y las periferias expandidas. Ampliando el concepto en Ciudad de México. Revista Latinoamericana de Estudios Urbano Regionales (EURE), 28(85), 121-149.

Alcaldia Mayor de Bogotá D.C. (2004). Decreto 190. Bogotá. http://www.alcaldiabogota.gov.co/sisjur/normas/Norma1.jsp?i=13935

Arango, G. (2009). Salvemos el espacio rururbano colombiano. Cuadernos de Vivienda y Urbanismo, 1(2), 394-409.

Ávila, H. (2005). Lo urbano-rural, ¿nuevas expresiones territoriales? Cuernavaca: Centro Regional de Investigaciones Multidisciplinarias (CRIM / UNAM).

Bahamón, G. (2009). Perímetros urbanos: Análisis del proceso de delimitación de espacialidades urbanas, un estudio de caso en Medellín. [Tesis de maestría, Universidad Nacional de Colombia]. Repositorio institucional unAL. http:// www.bdigital.unal.edu.co/3418/1/70561800.2009_1.pdf

Barros, C. (2006). La ciudad en el campo: nuevas ruralidades y lugares rururbanos. En J. Nogué y J. Romero (eds.), Las otras geografias (pp. 325-338). Valencia: Tirant Lo Blanch.

Boldrini, P. y Malizia, M. (2014). Procesos de gentrificación y contragentrificación. Los mercados de Abasto y del Norte en el Gran San Miguel de Tucumán (noroeste argentino). Revista INVI, 29(81), 157-191. 
Caballero, L. (2015). Del "no aprendi nada" al "hacerse escuchar". La construcción de subjetividades políticas y ciudadanias en una institución escolar de Bogotá. Nodos y Nudos, 4(38), 55-70. https://doi.org/10.17227/01224328.4321

Cámara de Comercio de Bogotá (2006). Cátedra abierta Bogotá en localidades: pasado, presente y futuro de la localidad de Usme. Bogotá: Autor.

Castaño, Y. (2014). Rurales metropolitanos: La emergencia de un nuevo grupo social. [Tesis de maestría, Universidad Nacional de Colombia]. Repositorio institucional UNAL.

Delgado, J. (2003), La urbanización difusa, arquetipo territorial de la ciudad-región. Sociológica, 18(51), 13-48.

Delgado, J. y Galindo, C. (2006). Los espacios emergentes de la dinámica rural-urbana. Problemas del Desarrollo, Revista Latinoamericana de Economía 37(147), 187-216.

Delgado, J. y Galindo, C. (2008). La difusión de la urbanización o cómo superar la dicotomía rural-urbana. En J. Delgado (ed.), La urbanización difusa de la ciudad de México. Otras miradas sobre un espacio antiguo (pp. 43-74). Ciudad de México: Instituto de Geografia-Universidad Nacional Autónoma de México (UNAM).

Fernández, J. (2007). Manizales rururbano. Aproximación al estudio de las condiciones para la sostenibilidad urbano rural del Municipio de Manizales. [Tesis de maestria, Universidad Nacional de Colombia]. Repositorio institucional UNAL.

Fraume, M. (2002). La trama rururbana en el desarrollo sostenible, avances conceptuales y metodológicos. Caso: cuenca hidrográfica del río Chinchiná. [Tesis de maestria, Universidad Nacional de Colombia]. Repositorio institucional UNAL.

Larrain, J. (2001). Identidad chilena. Santiago de Chile: LOM Ediciones.
Linck, T. (2001). El campo en la ciudad: reflexiones en torno a las ruralidades emergentes. Buenos Aires: Consejo Latinoamericano de Ciencias Sociales (Clacso). http://biblioteca.clacso.edu.ar/ar/libros/rjave/paneles/linck.pdf

Molina, W. (2011). Identidad regional en Magallanes, sus expresiones simbólicas y territoriales. Magallania, 39(1), 59-69.

Palma, H. (2007). Expresiones territoriales de la informalidad habitacional en el valle de la ciudad de Guatemala. Ciudad de Guatemala: Universidad de San Carlos de Guatemala.

Rubio, R. (2010). La transformación de los mercados laborales: el teletrabajo y sus alcances para el caso de Santiago, Chile. Revista de Geografía Norte Grande, 45, 119-134.

Secretaría Distrital de Planeación (SDP) (2011). 21 monografías de las localidades, Distrito Capital 2011. Bogotá: Alcaldia Mayor de Bogotá D.C.

Sereno, C., Santamaría, M. y Santarelli, S. (2010). El rururbano: espacio de contrastes, significados y pertenencia, ciudad de Bahia Blanca, Argentina. Cuadernos de Geografia: Revista Colombiana de Geografía, 19, 41-57.

Vargas, S. (2009). Ruralidades emergentes y dinámicas territoriales: nuevas percepciones y medios de vida. Eleuthera, 3, 194-205.

Villalvazo, P., Corona, J. y Garcia, S. (2002). Urbano-rural, constante búsqueda de fronteras conceptuales. Datos, Hechos y Lugares, 20, 17-24.

Zuluaga, G. (2005). Dinámicas territoriales en la frontera rural-urbana del corregimiento de Santa Elena, Medellín. [Tesis de maestria, Universidad Nacional de Colombia]. Repositorio institucional UNAL. 


\section{Diálogo del conocimiento}

Los diferentes procesos de desplazamiento que viven los habitantes del territorio colombiano a causa de cómo se ha distribuido la tierra en el pais, ha hecho que los espacios urbanos sufran un crecimiento exponencial principalmente a mediados del siglo pasado y con mayor intensidad en los últimos 30 años. El crecimiento de las ciudades se da hacia sus periferias lo que genera un acercamiento con los territorios rurales, y es justamente este cruce de fronteras del que da cuenta el presente artículo. El autor hace un ejercicio de leer estas formas de construcción de territorialidad que se dan en la frontera entre lo urbano y lo rural acudiendo al termino rururbanidad para dar mención al encuentro de estas dos culturas.

Lo rururbano da cuenta de unas formas identitarias construidas por los jóvenes que de origen rural asisten a colegios urbanos, y que encuentran en estas dos formas de socialización espacios territoriales desde los cuales comparten prácticas, jergas, rutinas y estilos de vida que permiten la construcción de esta forma de territorialidad que hibrida lo urbano y lo rural lo cual abre paso a una cultura juvenil rururbana.

El documento deja sobre la mesa varios interrogantes y asuntos a ser pensados. Por un lado, la comprensión de la identidad como una construcción no estática, lo que da lugar a pensar en la influencia de los contextos sobre ella y por el otro, las estructuraciones identitarias que hacen los jóvenes en el tránsito de una cultura a otra convirtiendo las fronteras en nuevos territorios desde los cuales se construyen identidades.

Adriana Patricia Mendoza Báez Profesora Facultad de Educación Universidad Pedagógica Nacional 